\title{
Excellent long-term reactivity of inhomogeneous nanoscale Fe-based metallic glass in wastewater purification
}

\author{
Shuang-Qin Chen ${ }^{1,2}$, Ke-Zhen Hui ${ }^{1 \dagger}$, Liang-Zheng Dong ${ }^{1 \dagger}$, Zhun $\mathrm{Li}^{3}$, Qing-hua Zhang ${ }^{4}$, Lin $\mathrm{Gu}^{4}$, \\ Wei Zhao ${ }^{1}, \mathrm{Si} \mathrm{Lan}^{2}$, Yubin $\mathrm{Ke}^{6}$, Yang Shao ${ }^{*}$, Horst $\mathrm{Hahn}^{2,5}$ and Ke-Fu Yao ${ }^{{ }^{*}}$
}

\begin{abstract}
Metallic glasses (MGs) have attracted great attention in wastewater treatment because of their high reactivity arising from amorphous structure, large residual stress and high density of low coordination sites. However, the reactivity of MGs would gradually slow down with time due to the passivation of active sites by corrosion products, resulting in limited long-term reactivity, which is also an unsolved key issue for established crystalline zero valent iron (ZVI) technology. Here, such problems are successfully overcome by introducing nanoscale chemical inhomogeneities in Fe-based MG (Fe-MGI), which apparently contributes to local galvanic cell effect and accelerates electron transfer during degradation process. More importantly, the selective depletion of $\mathrm{Fe}^{0}$ causes local volume shrinkage and crack formation, leading to self-peeling of precipitated corrosion products and reacted regions. Thereby fresh low coordination sites could be continuously provided, counteracting the mass transport and reactivity deteriorating problem. Consequently, Fe-MGI demonstrates excellent long-term reactivity and self-refreshing properties even in neutral solution. The present results provide not only a new candidate but also a new route of designing ZVI materials for wastewater treatment.
\end{abstract}

Keywords: Fe-based metallic glass, inhomogeneity, self-refreshing, wastewater treatment, catalysis

\section{INTRODUCTION}

Due to rapid increase in water pollution throughout the world, wastewater treatment has become a popular topic [1]. Over the past few decades, numerous materials and methods, such as bio-remediation [2], physical methods [3-5], and chemical methods [6,7] including processes with zero valent metals [8], Fenton catalysis [9-11], ozonation [12], and photocatalysis [13-15], have been developed for wastewater treatment. Among the chemical methods, zero valent iron (ZVI) technology is considered to be one of the most promising approaches because of its low cost, natural abundance, good performance, and ease of operation. The ZVI technology was successfully applied to permeable reactive barriers for the first time in 1991 and has subsequently attracted considerable attention [16]. However, the reactivity of ZVI always decreases with time because of electron transport and mass transfer limitations caused by surface passivation resulting from the precipitation of corrosion products [17]. These serious drawbacks are barriers that prevent the application of ZVI technology in large-scale wastewater treatment.

The formation of corrosion products is intrinsic to iron oxidization, and they begin to develop during the initial contact of ZVI with water [17]. Some countermeasures have been suggested to overcome this limitation. One is to eliminate the corrosion products from the surface of the aged ZVI by ultrasound or acid washing. Disadvantages of these measures are multifold: ultrasound technology requires a substantial energy input, and acid washing introduces an additional source of pollution. An

\footnotetext{
${ }^{1}$ School of Material Science and Engineering, Tsinghua University, Beijing 100084, China

${ }^{2}$ Herbert Gleiter Institute of Nanoscience, Nanjing University of Science and Technology, Nanjing 210094, China

${ }^{3}$ China Iron \& Steel Research Institute Group, Beijing 100081, China

${ }^{4}$ Beijing Laboratory for Electron Microscopy, Institute of Physics, CAS, Beijing 100190, China

${ }^{5}$ Institute of Nanotechnology, Karlsruhe Institute of Technology, 76344 Eggenstein-Leopoldshafen, Germany

${ }^{6}$ China Spallation Neutron Source, Institute of High Energy Physics, Chinese Academy of Sciences, Dongguan 523803, China

${ }^{\dagger}$ These authors contributed equally to this work.

* Corresponding authors (emails: shaoyang@tsinghua.edu.cn (Shao Y); kfyao@tsinghua.edu.cn (Yao KF))
} 
alternative is the development of novel ZVI with higher efficiency. For example, the combination of ZVI with one of the precious metals, which plays a role in catalytic hydrogenation and functions as the positive electrode of the galvanic cell accelerating ZVI corrosion and electron transport, improves the reactivity. Unfortunately, the ZVI bimetallic structures exhibit short lifetimes because of the build-up of a metal (hydr)oxide film and/or loss of the loosely bound precious metal particles.

Recently, superior degradation of azo dyes has been demonstrated in case of Fe-based metallic glasses (MGs), metastable modified ZVI materials, comparing with conventional crystalline ZVI [18-24]. Generally, MGs are readily obtained by quenching from the melt, avoiding crystallization that occurs upon rapid cooling [25]. Typically, MGs are metastable and show large residual stresses and a high density of low coordination sites, which have been shown to result in increased chemical reactivity [26]. The $\mathrm{Fe}_{78} \mathrm{Si}_{9} \mathrm{~B}_{13} \mathrm{MG}$ has been reported to possess extremely durable catalytic activity in acidic solution during advanced oxidation processes (AOP). In contrast, almost all the Fe-based MGs show limited longterm reactivity in neutral media and even worse reactivity in alkaline media, similar to conventional ZVIs.

More recently, we have reported that the $\left(\mathrm{Fe}_{73.5} \mathrm{Si}_{13.5} \mathrm{~B}_{9^{-}}\right.$ $\left.\mathrm{Nb}_{3} \mathrm{Cu}_{1}\right)_{91.5} \mathrm{Ni}_{8.5}$ multiphase nanocrystalline ribbons ( $\mathrm{Fe}-$ MNRs) exhibit higher reactivity than their single-phase MG counterpart due to the galvanic cell effect that originates from nanoscale chemical inhomogeneities and electrochemical potential differences between $\alpha$-Fe and the intermetallic phases $[27,28]$. Fe-MNRs show longterm durability with a high reactivity of 7 cycles in neutral solution because the selective corrosion of $\alpha$-Fe crystals results in the formation of three-dimensional (3D) nanoporous architectures that provide nano-pathways for efficient electron transport and mass transfer. Similarly, detrimental effects on the catalytic behavior were observed for the partially crystallized $\mathrm{Fe}_{73.5} \mathrm{Si}_{13.5} \mathrm{~B}_{9} \mathrm{Nb}_{3} \mathrm{Cu}_{1}$ and $\mathrm{Fe}_{78} \mathrm{Si}_{9} \mathrm{~B}_{13}$; however, the performance was almost completely restored in the fully crystallized materials due to the chemical inhomogeneities that existed in nanoscale [29]. Fully crystallized ribbons exhibited better catalytic performance over the $2^{\text {nd }}$ to $5^{\text {th }}$ cycles than the $1^{\text {st }}$ cycle, while the reported catalysts and ZVIs usually showed lower catalytic ability with increasing the number of cycles [29]. However, by annealing a Fe-MG to fabricate Febased crystallized ribbons, its metastable structure is lost and its partial intrinsic chemical reactivity is sacrificed. In addition, the annealing treatment consumes extra energy and thus increases the cost of wastewater treatment.
Therefore, if nanoscale chemical inhomogeneities can be introduced into a Fe-MG during processing, typically in the form of the homogeneous distribution of atoms in a disordered structure, a desirable ZVI can be obtained. In such structures, both the galvanic cell effect, which originates from chemical inhomogeneities and the excellent intrinsic characteristics (large residual stress, metastable nature, and high density of low coordination sites) of MG can be combined. In the present work, we fabricated Febased MG ribbons with quenched-in nanoscale chemical inhomogeneities, i.e., Fe-MGI, by carefully selecting and optimizing the alloy composition (to be discussed later), and thus demonstrated the superior degradation properties using these materials. More interestingly, the cycling capability significantly improved up to 45 cycles, which can be attributed to a self-peeling process induced by selective corrosion/de-alloying of the Fe-MGI.

\section{EXPERIMENTAL SECTION}

\section{Materials preparation and characterization}

An alloy ingot with a nominal composition of $\mathrm{Fe}_{81} \mathrm{Si}_{4} \mathrm{~B}_{14^{-}}$ $\mathrm{Cu}_{1}$ (at.\%) was produced by induction melting of an Fe-B master alloy and high-purity (99.5\%-99.9\%) elemental Fe, $\mathrm{Si}$, and $\mathrm{Cu}$. The resulting alloy ingot was then used to prepare $\mathrm{Fe}$-based MG with nanoscale inhomogeneities by melt-spinning, and hereafter the as-cast $\mathrm{Fe}_{81} \mathrm{Si}_{4} \mathrm{~B}_{14} \mathrm{Cu}_{1}$ is referred to as Fe-MGI. Prepared ribbons with a thickness of $\sim 23 \mu \mathrm{m}$ were cut into $10 \mathrm{~mm} \times 10 \mathrm{~mm}$ pieces for subsequent use in degradation experiments. Structural identification of the as-cast ribbons was carried out by $\mathrm{X}$ ray diffraction (XRD, Rigaku D/max-RB) with $\mathrm{Cu} \mathrm{Ka}$ radiation and high-resolution transmission electron $\mathrm{mi}-$ croscopy (HRTEM, JEOL JEM-2010F). The thermal properties of the as-cast ribbons were characterized by differential scanning calorimetry (DSC, NETZSCH STA409 C/CD). The surface morphology and cross section of the ribbons before and after the degradation experiments were observed by scanning electron microscopy (SEM, ZEISS Merlin). Energy-dispersive Xray spectroscopy (EDS) through a SEM and spherical aberration-corrected high-angle annular dark-field scanning TEM (HAADF-STEM, JEM ARM200CF) were performed to examine the elemental distribution at the microscale and nanoscale, respectively.

To further confirm the structure of Fe-MGI, the small angle neutron scattering (SANS) measurements were carried out at the China Spallation Neutron Source (CSNS) [30]. Incident neutrons with wavelengths of 1-9 $\AA$ were selected using a double-disc bandwidth 
chopper, which was collimated to the sample by a pair of apertures. In the experiments, a sample to detector distance of $4 \mathrm{~m}$ and sample aperture of $6 \mathrm{~mm}$ were used. A $1 \mathrm{~m}$ square detector array was used composed of 120 linear ${ }^{3} \mathrm{He}$ gas tubes with a diameter of $8 \mathrm{~mm}$, covering a Q-range of $0.01-1 \AA^{-1}$. For each sample, the presented data were collected over $\sim 120 \mathrm{~min}$ at $50 \mathrm{~kW}$. Neutron data are corrected for background scattering (empty sample holder), transmission and detector efficiency, and set to absolute units.

Open circuit potential (OCP), electrochemical impedance spectra (EIS), and potentiodynamic polarization measurements were carried out on a CHI660 electrochemical workstation ( $\mathrm{CH}$ Instruments Ins) using a three-electrode cell comprising a platinum counter electrode (CE), a standard $\mathrm{Ag} / \mathrm{AgCl}$ reference electrode, and the MGI or MG samples with a surface area of $0.5 \mathrm{~cm}^{2}$ as the working electrode. A $25 \mathrm{mg} \mathrm{L}^{-1}$ Orange II solution was prepared from analytical reagents and deionized water at room temperature and used as an electrolyte. A sweep rate of $0.333 \mathrm{mV} \mathrm{s}^{-1}$ was used throughout the potentiodynamic polarization tests. EIS measurements were carried out at an AC amplitude of $5 \mathrm{mV}$ over frequencies ranging from $10^{-2}-10^{5} \mathrm{~Hz}$ at a stabilized OCP.

\section{Testing of the degradation and catalytic properties}

The azo dye, Orange II $\left(\mathrm{C}_{16} \mathrm{H}_{11} \mathrm{~N}_{2} \mathrm{SO}_{4} \mathrm{Na}\right)$, was purchased from Sinopharm Chemical Reagent Beijing Co., Ltd. (Beijing, China). Dye solutions were prepared by dissolving Orange II powder into deionized water. The initial $\mathrm{pH}$ values of dye solutions were adjusted accordingly using hydrochloric acid or sodium hydroxide. The temperatures of the azo dye solutions were controlled by water bath during the degradation experiments, stirred at a fixed speed of $180 \mathrm{rpm}$. At fixed time intervals, $4 \mathrm{~mL}$ of solution was extracted by syringe, filtered through a $0.22 \mu \mathrm{m}$ membrane, and then scanned using a UV-vis spectrophotometer (Unico UV-2802PC) to obtain absorbance spectra. The concentrations of Orange II were quantified by measuring the absorption intensity at a maximum of $484 \mathrm{~nm}$, which originates from the azo chromophore. For quantitative evaluation, the degradation curves were fitted using a pseudo first order kinetic model, which has been applied to many ZVI degradation systems:

$C / C_{0}=\exp \left(-k_{\mathrm{obs}} t\right)$,

where $C$ is the concentration of Orange II, $C_{0}$ is the initial concentration of Orange II, $k_{\mathrm{obs}}$ is the observed reaction rate constant, and $t$ is the reaction time. The degradation efficiency was calculated using $\left(\eta=\left(1-C_{t} / C_{0}\right) \times 100 \%\right.$, where $C_{t}$ is the concentration of Orange II at a treatment time of $t$, and the half-life $t_{1 / 2}$ is the time it takes for $C$ to become half of $C_{0}$, to estimate the degradation capability.

To compare the degradation capability of Fe-MGI with other materials, commercial crystalline ZVI powder (C$\mathrm{ZVI})$ and $\mathrm{Fe}_{73.5} \mathrm{Si}_{13.5} \mathrm{~B}_{9} \mathrm{Nb}_{3} \mathrm{Cu}_{1}$ MG (Fe-MG) were evaluated under the same experimental conditions. The surface morphologies and structures of $\mathrm{Fe}^{0}$ powder and $\mathrm{Fe}_{73.5} \mathrm{Si}_{13.5} \mathrm{~B}_{9} \mathrm{Nb}_{3} \mathrm{Cu}_{1}$ MG were characterized by XRD and SEM (Fig. S1). To examine its adaptability to the environment, the Fe-MGI was subjected to Orange II solutions with different initial concentrations $\left(C_{0} \mathrm{~s}\right)$, temperatures, and $\mathrm{pH}$ values. To evaluate the catalytic properties of Fe-MGI, the degradation of Methylene Blue (MB) was carried out in Fenton-like solutions with various different treatment parameters.

Cycling experiments were performed to evaluate the long-term reactivity of Fe-MGI. First, an Orange II solution with a $C_{0}$ of $100 \mathrm{mg} \mathrm{L}^{-1}$ and an initial $\mathrm{pH}$ value of 6 was prepared. Then $2.5 \mathrm{~g}$ of Fe-MGI was placed into a $250 \mathrm{~mL}$ Orange II solution. During the degradation process, the solution was held at a temperature of $25^{\circ} \mathrm{C}$ and stirred at fixed speed of $180 \mathrm{rpm}$. After $50 \mathrm{~min}$, the degraded solution was removed and $250 \mathrm{~mL}$ of fresh Orange II solution was added to the used Fe-MGI without washing. This process was replicated until the degradation capability of the Fe-MGI was observed to significantly deteriorate.

\section{RESULTS}

\section{Characterization of Fe-MGI}

In order to understand the correlation between structure and properties, the Fe-MGI was initially characterized by XRD. As can be seen in Fig. 1a, the XRD pattern exhibits two broad humps at around $45^{\circ}$ and $80^{\circ}$, clearly indicating the amorphous nature of Fe-MGI. The calorimetric analysis by DSC shown in Fig. 1b exhibits two exothermic peaks corresponding to a two-stage amorphous to crystalline transformation, in agreement with the amorphous structure of Fe-MGI.

The structure and morphology of Fe-MGI were examined with higher lateral resolution using HRTEM and HAADF-STEM. The HRTEM image in Fig. 1c exhibits a typical isotropic maze contrast, while the selected area electron diffraction pattern shows amorphous rings (inset in Fig. 1c), both of which are clear indications of the MG structure in the as-prepared ribbons. In addition, some circular/spherical regions in the size range of 3-5 $\mathrm{nm}$ are noticeable in the MG matrix. Combined with the HAADF 

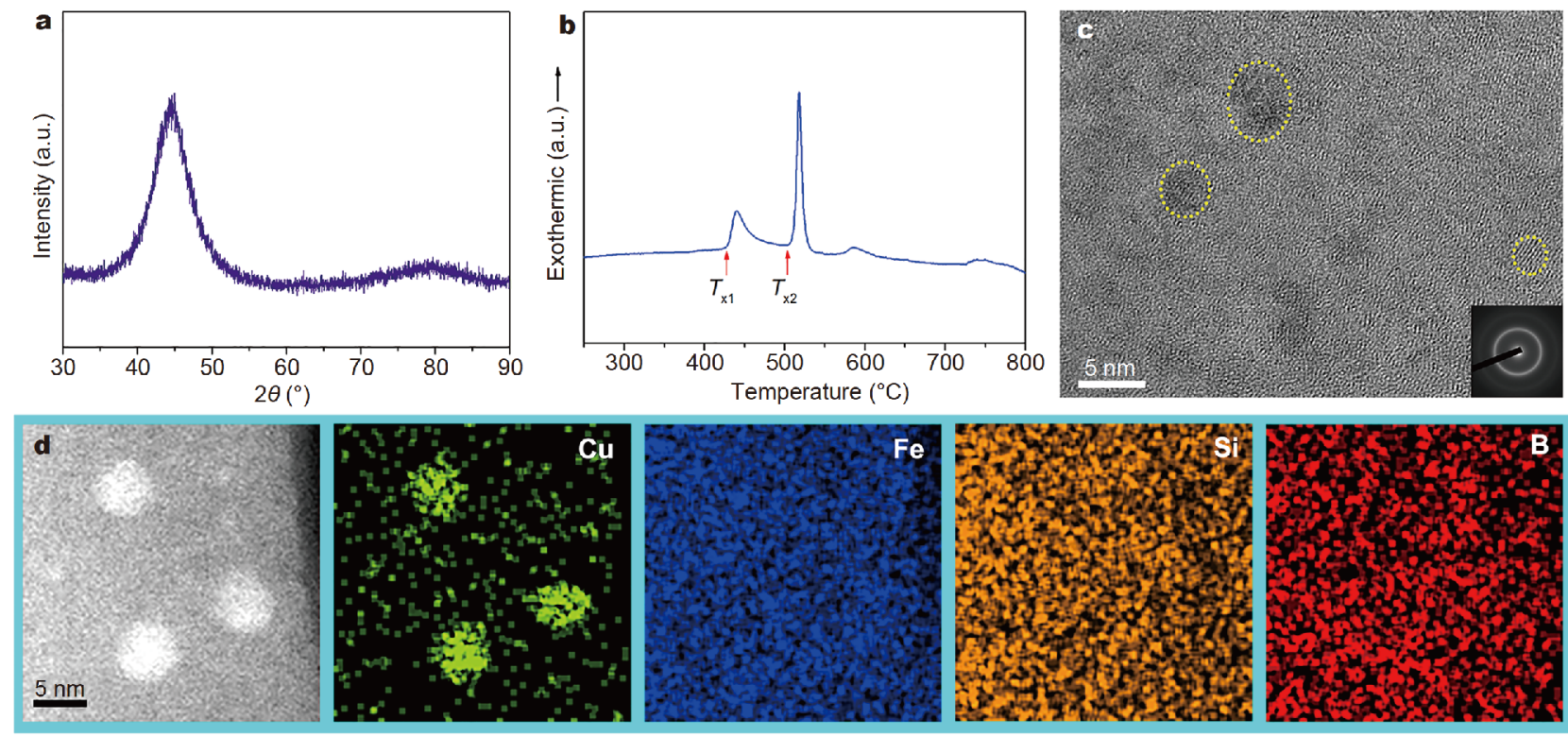

Figure 1 (a) XRD pattern, (b) DSC curve, (c) HRTEM image and (d) HAADF image and its corresponding EDS images of Fe-MGI.

and EDS images (Fig. 1d), these regions can be identified as copper-rich clusters, which is a clear indication of the phase separation within the amorphous matrix. The iron concentration in the copper-rich regions is expected to be lower than in the surrounding areas due to the positive enthalpy of mixing between $\mathrm{Cu}$ and $\mathrm{Fe}$ and their intrinsic immiscibility [31,32]. However, no significant heterogeneous distribution of iron, or of the other constituent elements, was observed. The reasons for the discrepancy between expectation and actual experimental evidence could be manifold: one reason could be the detection limits of STEM or the overlapping areas above and below the $\mathrm{Cu}$-rich particles. In any case, from the present results it can be concluded that the as-cast Fe-MGI exhibits nanoscale chemical inhomogeneities, which are composed of 3-5 nm copper-rich clusters distributed in an MG matrix with little or no $\mathrm{Cu}$.

To avoid devitrification induced by ion milling, a TEM film was also prepared by double-side jet thinning. More TEM images showing the Fe-MGI inhomogeneities can be found in the Supplementary information (Fig. S2). To further exclude any possibility of induced devitrification during TEM film preparation by ion milling or two-jet thinning, the presence of inhomogeneities embedded in the homogenous amorphous state of the as-cast Fe-MGI was confirmed by SANS (Fig. S3) [33].

\section{Degradation capability}

Orange II, a typical azo dye that cannot be degraded by microorganism, was chosen as a model pollutant to examine the degradation capability, environmental adaptability and long-term reactivity of Fe-MGI.

For comparison, experiments on the degradation of Orange II by Fe-MGI, Fe-MG, and C-ZVI were carried out. As shown in Fig. 2a, the degradation capability of FeMGI is substantially higher than those of Fe-MG without inhomogeneities and C-ZVI. As shown in Fig. 2b, the intensity of the characteristic peak at $484 \mathrm{~nm}$ for the azo bond $(-\mathrm{N}=\mathrm{N}-)$ decreases with reaction time, indicating bond breakage. As shown in Fig. 2c, the peak at $227 \mathrm{~nm}$ with a shoulder at $250 \mathrm{~nm}$ arising from 1-amino-2naphthol $(1 \mathrm{~A} 2 \mathrm{~N})$ and the peaks at 197 and $248 \mathrm{~nm}$ originating from sulfanilic acid (SA) can be identified in the spectra of the decomposition products of Orange II, further verifying $-\mathrm{N}=\mathrm{N}-$ bond breakage. These results suggest that the decomposition mechanism of Orange II by Fe-MGI is consistent with that of C-ZVI (Fig. S4), that is, $\mathrm{Fe}^{0}$ donates electrons to electron-deficient $-\mathrm{N}=\mathrm{N}-$ bonds to decompose the Orange II into two components (SA and $1 \mathrm{~A} 2 \mathrm{~N}$ ).

The high degradation capability of Fe-MGI most likely originates from its good intrinsic electron transport properties due to the formation of nanoscale inhomogeneities within the amorphous structure. As shown in Fig. 3a, the OCP of Fe-MGI shifts to a lower potential from -640 to $-656 \mathrm{mV}$ after 5 degradation cycles of Orange II, indicating that it sustains surface reactivity in Orange II solution without passivation. On the contrary, 

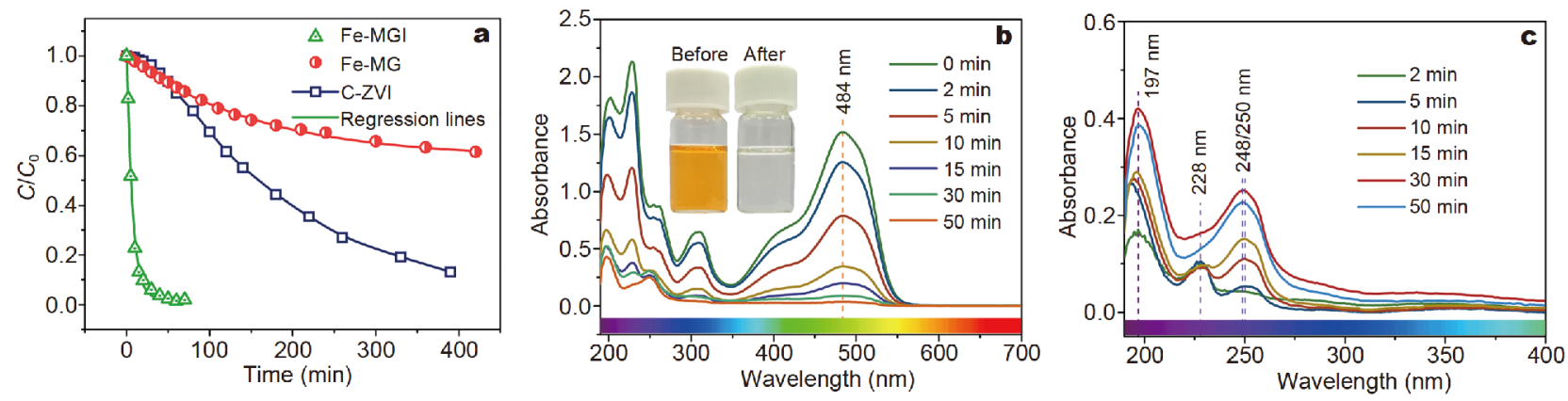

Figure 2 (a) Degradation curves of Fe-MGI, Fe-MG and C-ZVI. UV-vis absorption spectra of Orange II by Fe-MGI (b) and the decomposition products of Orange II degraded by Fe-MGI (c). Experimental conditions: $C_{0}$ of $25 \mathrm{mg} \mathrm{L}^{-1}$, solution volume of $250 \mathrm{~mL}$, ribbon dosage of $10 \mathrm{~g} \mathrm{~L}^{-1}$, temperature of $25^{\circ} \mathrm{C}, \mathrm{pH}$ value of 6 .
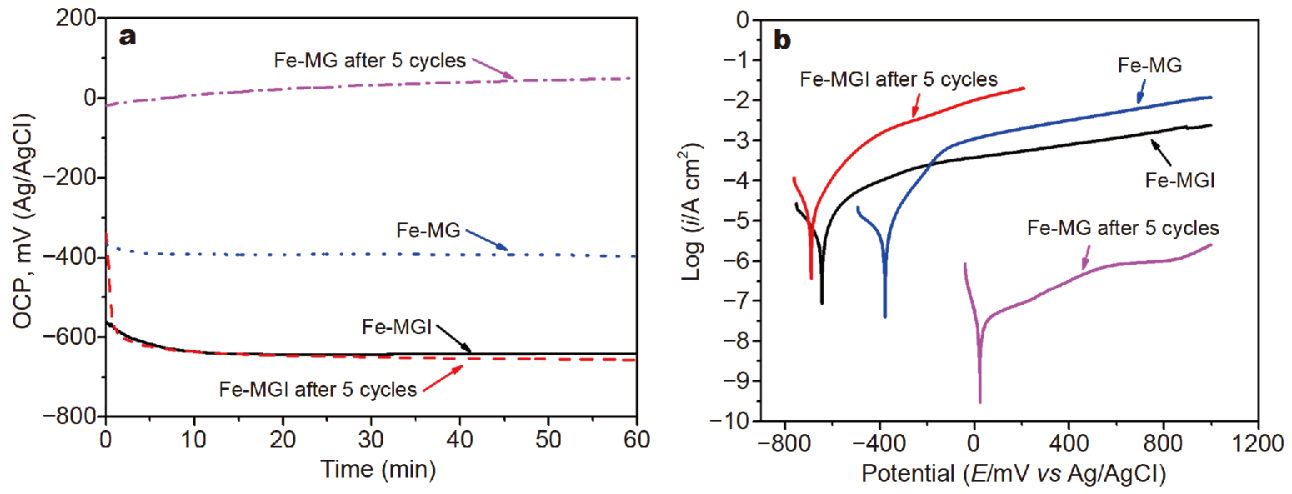

Figure 3 (a) OCP curves and (b) potentio-dynamic polarization curves of Fe-MGI and Fe-MG before and after the degradation of Orange II.

the OCP of Fe-MG undergoes a significant positive shift from -392 to $+48 \mathrm{mV}$ after degradation, suggesting passive film formation during the degradation of Orange II. As shown in Fig. 3b, the corrosion potential $\left(E_{\text {corr }}\right)$ of FeMGI decreases from -642 to $-687 \mathrm{mV}$ after the degradation of Orange II and the corrosion current of used Fe-MGI $\left(i_{\text {corr }}=8.8 \mu \mathrm{A} \mathrm{cm}^{-2}\right)$ is higher than that of fresh Fe-MGI $\left(i_{\text {corr }}=1.63 \mu \mathrm{A} \mathrm{cm}^{-2}\right)$. In contrast, the $E_{\text {corr }}$ of $\mathrm{Fe}$ MG increases from -377 to $+25 \mathrm{mV}$ and the $i_{\text {corr }}$ decreases from 1.59 to $1.51 \times 10^{-2} \mu \mathrm{A} \mathrm{cm}^{-2}$ after the degradation of Orange II. These results demonstrate that Fe-MGI exhibits higher occurrence of oxidation than FeMG, i.e., higher surface reactivity and faster electron transport in Orange II solution. As shown in Fig. 4, the typical surface morphology for selective corrosion, i.e., a nanoporous structure, can be observed, demonstrating the formation of galvanic cells. Moreover, corrosion products with flower-like structures, large surface areas, and adsorption properties on the surface of Fe-MGI are also beneficial in terms of degradation capability of the material. Thus, Fe-MGI shows much higher degradation
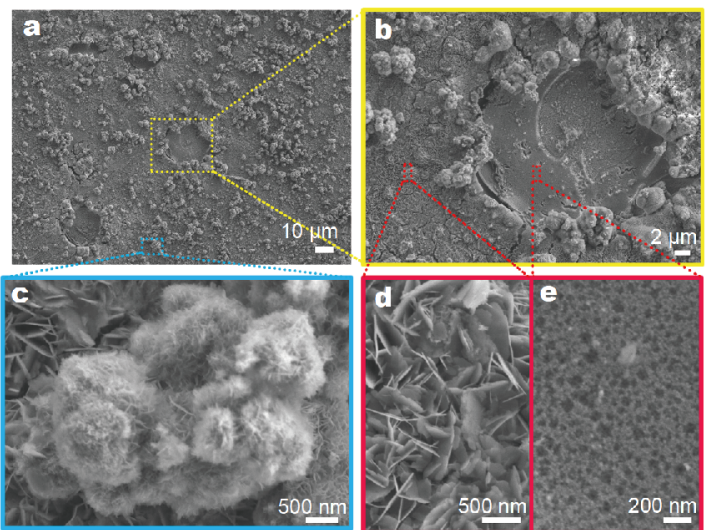

Figure 4 SEM images of Fe-MGI's surface morphologies after degradation of Orange II: (a) at low magnefication, (b) enlarged reacted region, (c) and (d) enlarged flowerlike structure corrosion products, and (e) further enlarged nanoporous reacted regions. Experimental conditions: $C_{0}$ of $25 \mathrm{mg} \mathrm{L}^{-1}$, solution volume of $250 \mathrm{~mL}$, ribbon dosage of $10 \mathrm{~g} \mathrm{~L}^{-1}$, temperature of $25^{\circ} \mathrm{C}, \mathrm{pH}$ value of 6 .

capability than Fe-MG, which can be attributed to enhanced electron transport and mass transfer due to its 
nanoporous structure and increased surface area.

\section{Environmental adaptability}

Since wastewater and contaminated aqua-systems are complicated mixtures of components, which has a significant effect on the sequestration of contaminants, the influences of environmental parameters, such as concentration, temperature, and $\mathrm{pH}$ value, on the degradation of Orange II by Fe-MGI were investigated.

As shown in Fig. 5a, a high degradation efficiency of above 95\% was obtained within $30 \mathrm{~min}$ for Orange II solutions with $C_{0}$ of $25-100 \mathrm{mg} \mathrm{L}^{-1}$, which demonstrates that Fe-MGI shows good performance for the degradation of different concentrations of Orange II. As shown in Fig. 5b, the degradation efficiency of Fe-MGI increases from $90 \%$ to $99 \%$ within $20 \mathrm{~min}$ and the $t_{1 / 2}$ decreases from 5.2 to $2.3 \mathrm{~min}$ upon an increase in the temperature from 25 to $55^{\circ} \mathrm{C}$. Based on the $k_{\text {obs }}$ at different temperatures $(T)$, the activation energy $\left(E_{\mathrm{a}}\right)$, an intrinsic kinetic characteristic of catalysts that reflects the energy barrier of catalytic reactions, can be calculated using the Arrhenius equation, $\ln k_{\mathrm{obs}}=-E_{\mathrm{a}} / R T+\ln A$, where $R$ is the gas constant and $A$ is a pre-exponential factor. As shown in Fig. $5 \mathrm{c}$, the $E_{\mathrm{a}}$ can be calculated to be $20.3 \mathrm{~kJ} \mathrm{~mol}^{-1}$. As shown in Fig. 5d, different from most ZVIs, which can only be applied in acid solutions, Fe-MGI exhibits high degradation capability of Orange II in solution with $\mathrm{pH}$ values of $2-10$. At an initial $\mathrm{pH}$ value of 10 , the degradation efficiency of Orange II degraded by Fe-MGI is up to $97 \%$ within $40 \mathrm{~min}$, which is much higher than the $7 \%$ within $40 \mathrm{~min}$ achieved by C-ZVI at $\mathrm{pH} 6$, and $70 \%$ within $40 \mathrm{~min}$ for Fe-MNRs at $\mathrm{pH} 10$ [28], as well as compared to most other reported catalysts operating under alkaline conditions (Table S1)[19,34-37]. This can be attributed to the catalytic hydrogenation and formation of galvanic cells due to the inherent nanoscale inhomogeneities present in the structure of Fe-MGI. The additionally observed flower-like corrosion products on the surface (Fig. 6) increase the specific surface area and then obviously contribute to the high performance of $\mathrm{Fe}$ MGI [38,39]. After investigating the influence of concentration, temperature, and $\mathrm{pH}$, it can be seen that $\mathrm{Fe}$ MGI exhibits good environmental adaptability.

\section{Catalytic properties}

The performance of Fe-MGI as a catalyst in a hetero-
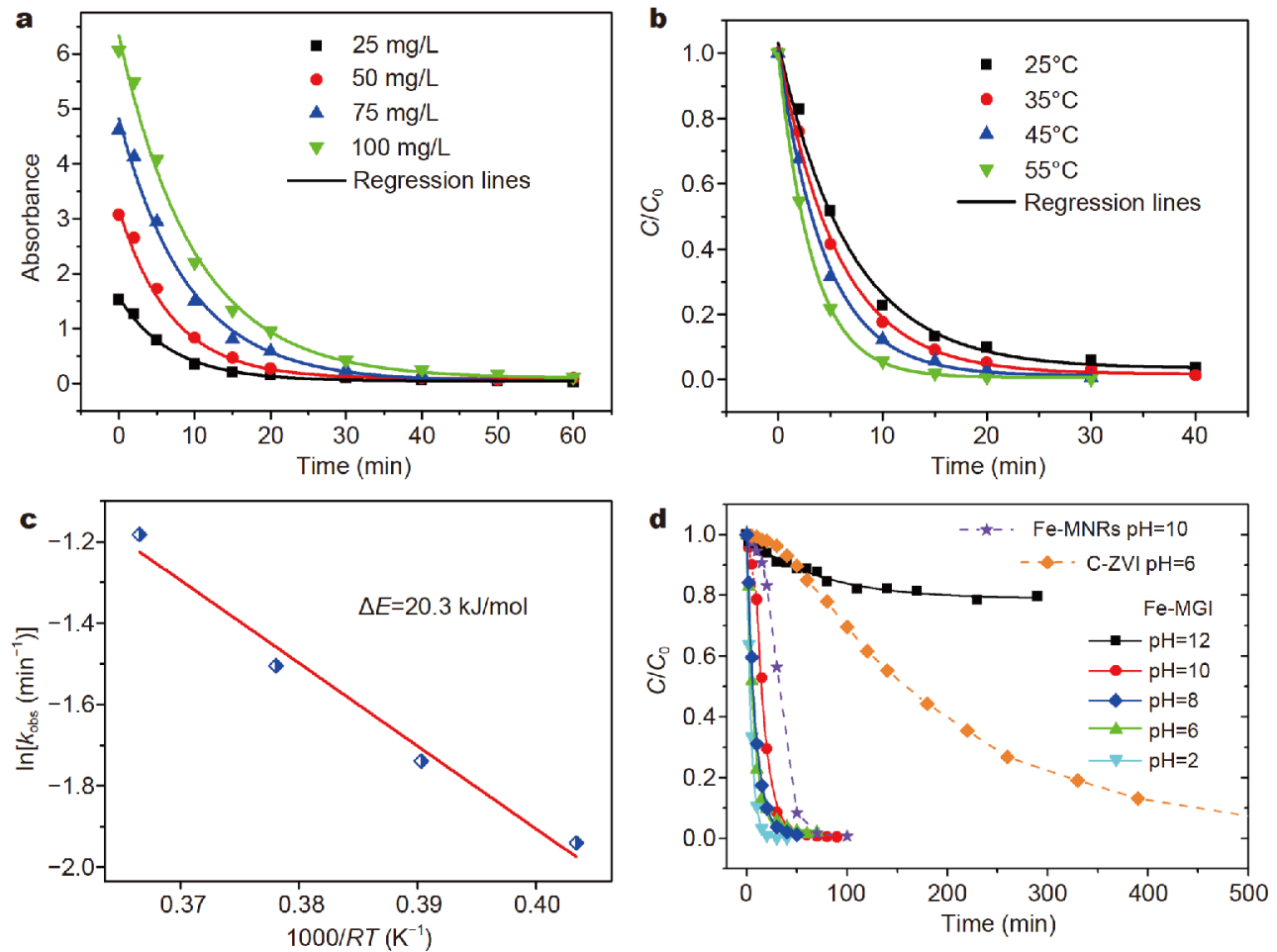

Figure 5 Degradation curves of Fe-MGI under different environments: (a) various $C_{0}$ s of Orange II, (b) environment temperatures, (c) the Arrhenius plot for the estimation of the activation energy in degradation of Orange II by Fe-MGI, and (d) different $\mathrm{pH}$ values. Experimental conditions: $C_{0}$ of $25 \mathrm{mg} \mathrm{L}^{-1}$, solution volume of $250 \mathrm{~mL}$, ribbon dosage of $10 \mathrm{~g} \mathrm{~L}^{-1}$, temperature of $25^{\circ} \mathrm{C}, \mathrm{pH}$ value of 6 , except for noted variates. 

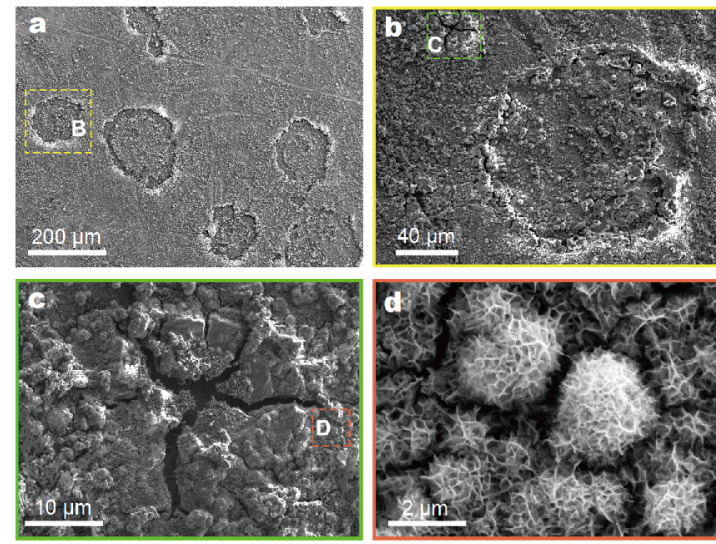

Figure 6 SEM images of the surface morphology of Fe-MGI after degradation of Orange II solution at $\mathrm{pH} 10$, (a) low enlarged scale SEM image, (b) enlarged reacted region corresponded $\mathrm{B}$ region in (a), (c) enlarged cracks in precipitated products corresponded $\mathrm{C}$ region in (b), and (d) enlarged precipitated products corresponded D region in (c). Experimental conditions: $C_{0}$ of $25 \mathrm{mg} \mathrm{L}^{-1}$, solution volume of $250 \mathrm{~mL}$, ribbon dosage of $10 \mathrm{~g} \mathrm{~L}^{-1}$, temperature of $25^{\circ} \mathrm{C}$.

geneous Fenton-like process, a well-known AOP [12], was evaluated by studying the degradation of $\mathrm{MB}$ as a model pollutant under various treatment conditions. First, the effect of catalyst dosage was investigated. As shown in Fig. 7a, a negligible degradation efficiency of $8 \%$ was detected within $30 \mathrm{~min}$ in absence of Fe-MGI catalyst, indicating that $\mathrm{H}_{2} \mathrm{O}_{2}$ is incapable of effectively degrading the MB. However, a higher degradation efficiency of MB was achieved during Fenton-like oxidation using Fe-MGI as a catalyst. For instance, efficiencies of up to 99\% after 15 min of degradation reaction were obtained for dosages of $0.2,0.5,1$, and $2 \mathrm{~g} \mathrm{~L}^{-1}$. In Fenton-like reactions, the initial $\mathrm{H}_{2} \mathrm{O}_{2}$ concentration is also critical. As shown in Fig. 7b, at a dosage of $0.5 \mathrm{~g} \mathrm{~L}^{-1}$, Fe-MGI cannot effectively degrade $\mathrm{MB}$ dye without the addition of $\mathrm{H}_{2} \mathrm{O}_{2}$, as indicated by the degradation efficiency of only $8 \%$ after $30 \mathrm{~min}$. The $k_{\mathrm{obs}}$ increases sharply from 0.04 to $0.48 \mathrm{~min}^{-1}$ upon an increase in the concentration of $\mathrm{H}_{2} \mathrm{O}_{2}$ from 0 to $2 \mathrm{mmol} \mathrm{L}^{-1}$ and degradation efficiencies of $1 \%, 94 \%, 99 \%$, and $99 \%$ were observed for solutions with concentrations of $0,0.5,1$, and $2 \mathrm{mmol} \mathrm{L}^{-1}$ of $\mathrm{H}_{2} \mathrm{O}_{2}$, respectively. $\mathrm{Hy}$ droxyl radicals $(\cdot \mathrm{OH})$ is the primary decomposer of azo dyes, produced after the addition of $\mathrm{H}_{2} \mathrm{O}_{2}$. Thus, the degradation efficiencies and $k_{\mathrm{obs}}$ increase remarkably upon an increase in the concentration of $\mathrm{H}_{2} \mathrm{O}_{2}$. As seen from Fig. $7 \mathrm{c}$, when the $\mathrm{MB}$ dye concentration is increased from 20 to $120 \mathrm{mg} \mathrm{L}^{-1}$, the $k_{\text {obs }}$ decreases from 0.32 to $0.16 \mathrm{~min}^{-1}$ and the efficiency declines from $99 \%$ to $79 \%$ after $15 \mathrm{~min}$. Fig. $7 \mathrm{~d}$ shows the effect of the $\mathrm{pH}$ values of the solution on the catalytic properties. It can be seen that both degradation efficiency and $k_{\text {obs }}$ are sensitive to $\mathrm{pH}$ values of 2 and 3, but much lower catalytic properties are observed in near neutral solutions. Fig. 7e shows the influence of solution temperature on the catalytic properties of Fe-MGI. The $k_{\text {obs }}$ increases sharply from 0.32 to $1.05 \mathrm{~min}^{-1}$ upon an increase in the temperature from 25 to $55^{\circ} \mathrm{C}$, around a three-fold improvement. As shown in Fig. $7 \mathrm{f}$, the $E_{\mathrm{a}}$ of the Fe-MGI catalyst in this work is $34.2 \mathrm{~kJ} \mathrm{~mol}^{-1}$, a value lower than observed for crystalline alloys and comparable to those of MG catalysts [40]. After comparing the degradation efficiencies and $k_{\mathrm{obs}}$ in $\mathrm{MB}$ dye solutions with or without the Fe-MGI catalyst, in the presence of different $\mathrm{H}_{2} \mathrm{O}_{2}$ concentrations, dye concentrations, temperatures, and $\mathrm{pH}$ values, it can be concluded that Fe-MGI shows good catalytic properties for Fenton-like processes in acid solutions.

\section{Long-term reactivity}

Poor long-term reactivity is one of the major intrinsic limitations of ZVI toward contaminant removal, due to the surface passivation caused by the formation of corrosion products, such as $\mathrm{Fe}(\mathrm{OH})_{2}, \mathrm{Fe}(\mathrm{OH})_{3}$, and/or metal carbonates. Hence, it is essential and of great significance to investigate the cycling performance of Fe-MGI.

As shown in Fig. 8a, Fe-MGI maintains fast kinetics and high efficiencies up to 45 cycles in the degradation of Orange II. More detailed parameters, such as $k_{\text {obs }}$, half-life $\left(t_{1 / 2}\right)$, and the degradation efficiency at $50 \mathrm{~min}\left(\eta_{50 \mathrm{~min}}\right)$ of Fe-MGI versus the number of cycles, can be found in Fig. $8 \mathrm{~b}$ and Table S2. For example, $k_{\text {obs }}$ fluctuates within 0.135-0.097 $\mathrm{min}^{-1}$ up to the $36^{\text {th }}$ cycle. Thereafter, the $k_{\text {obs }}$ declines to $0.027 \mathrm{~min}^{-1}$ during the $51^{\text {st }}$ cycle, but goes up and down between 0.014 and $0.033 \mathrm{~min}^{-1}$ during the $52^{\text {nd }}$ to $60^{\text {th }}$ cycles, indicating that Fe-MGI still maintains its reactivity.

The $\eta_{50 \mathrm{~min}}$ values are up to $90 \%$ and $85 \%$ at the $40^{\text {th }}$ and the $45^{\text {th }}$ cycles, respectively. Thereafter, the $\eta_{50 \text { min }}$ values decline gradually to $24 \%$ during the $60^{\text {th }}$ cycle. The $t_{1 / 2}$ of Orange II degraded by Fe-MGI remains short within 45 cycles, then increases rapidly from $13.4 \mathrm{~min}$ at the $45^{\text {th }}$ cycle to $103 \mathrm{~min}$ at the $55^{\text {th }}$ cycle. Upon a further increase in the number of cycles, the concentration of Orange II in the solution cannot be degraded to half of the $C_{0}$. All these results demonstrate that Fe-MGI shows superior long-term reactivity with high degradation capability up to 45 cycles, while even with the assistance of ultrasonic washing, the maximum number of cycles reported for a sustainable ZVI in the dye degradation of MGs without nanoscale chemical inhomogeneity, can only be 30 cycles (Fig. 9) $[19,28,34,35,41-46]$. The durability of the present 

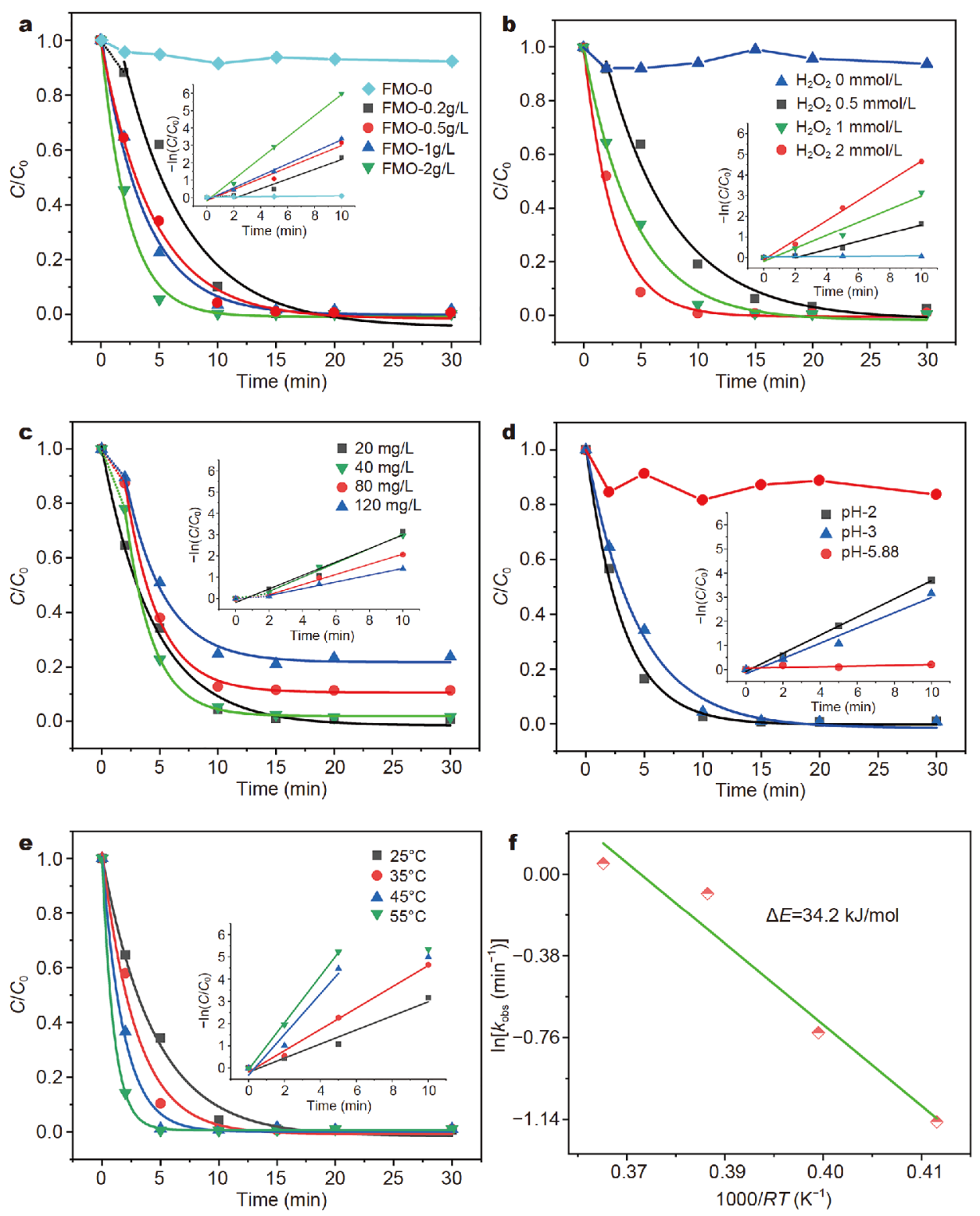

Figure 7 Catalytic properties of Fe-MGI evaluated by degradation of MB in Fenton-like process using various treatment parameters: (a) dosages of Fe-MGI, (b) concentrations of $\mathrm{H}_{2} \mathrm{O}_{2}$, (c) $\mathrm{C}_{0} \mathrm{~s}$ of $\mathrm{MB}$, (d) initial $\mathrm{pH}$ values and (e) temperatures. (f) The Arrhenius plot for the estimation of the activation energy. If not mentioned, experimental conditions are $C_{0}$ of $20 \mathrm{mg} \mathrm{L}^{-1}$, solution volume of $250 \mathrm{~mL}$, ribbon dosage of $0.5 \mathrm{~g} \mathrm{~L}{ }^{-1}$, temperature of $25^{\circ} \mathrm{C}$ and $\mathrm{pH}$ value of 3 .

system is even more stable than those of the most recently reported Fe-MGs with excellent sustainability that can be reused about 35 times [40]. Therefore, Fe-MGI shows sustainable long-term high reactivity.

\section{DISCUSSION}

To investigate the superior long-term reactivity of FeMGI in wastewater treatment, the surface morphology of the ribbons before and after cycling was studied to obtain additional evidence of the surface-mediated process of azo dye degradation. As shown in Fig. 10a, prior to the start of the degradation experiments, Fe-MGI exhibits a shiny surface, but after cycling, the ribbon surface structure has completely changed to a smaller net-like structure with many holes, implying a self-peeling off of Fe-MGI during cycling. As shown in Fig. 10b, the holes appear to consist of one or several circular regions of reacted material with sizes varying from micrometers to 

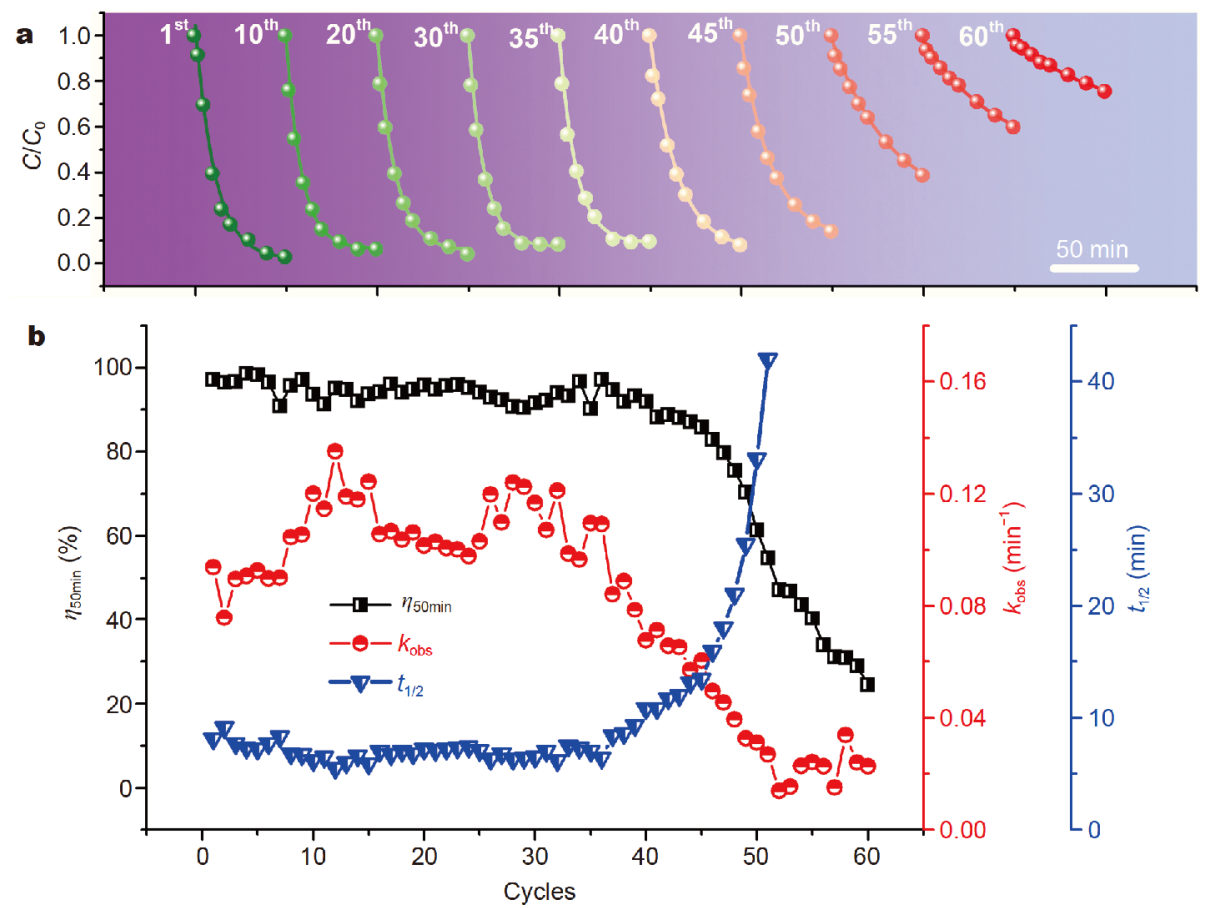

Figure 8 (a) Cyclic degradation curves of Orange II solution with $C_{0}$ of $100 \mathrm{mg} \mathrm{L}^{-1}$ by Fe-MGI, and (b) degradation efficiency within 50 min $\left(\eta_{50 \mathrm{~min}}\right)$, half-life $\left(t_{1 / 2}\right)$ and the observed degradation rate $\left(k_{\mathrm{obs}}\right)$ as a function of cycles. Experimental condition: $C_{0}$ of $100 \mathrm{mg} \mathrm{L}^{-1}$, solution volume of $250 \mathrm{~mL}$, ribbon dosage of $10 \mathrm{~g} \mathrm{~L}^{-1}$, temperature of $25^{\circ} \mathrm{C}, \mathrm{pH}$ value of 6 .

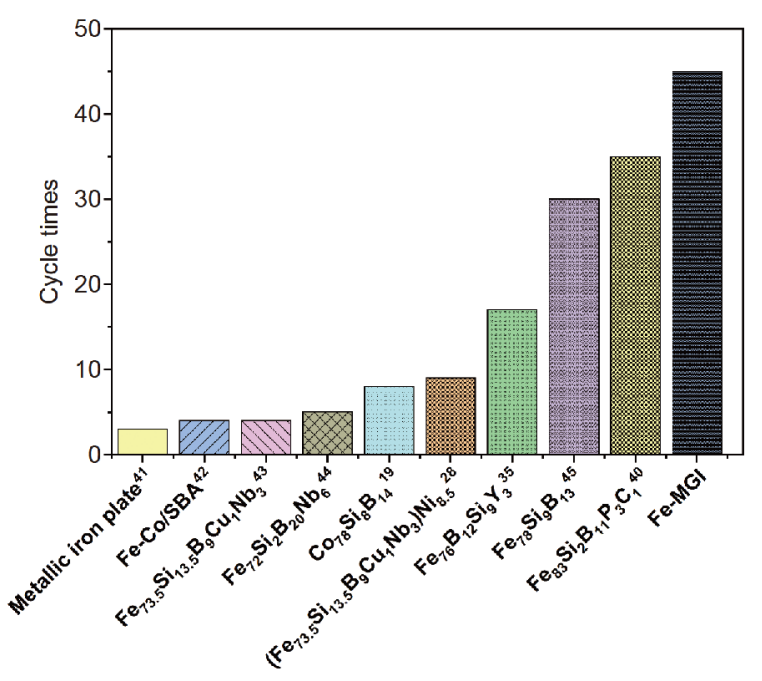

Figure 9 Available cycling data of different reported ZVIs compared with the Fe-MGI prepared in this work.

millimeters. The remaining skeleton of the structured ribbons contain many cracks with widths ranging from hundred nanometers to micrometers (Fig. 10c-e), indicative of large internal stresses that are greater than the critical stresses of Fe-MGI. Fig. 10d shows an enlarged
SEM image corresponding to the main reacted region (D region) in Fig. 10b. There is a distinct circular crack (Fig. 10d and Fig. S5) between the reacted region and the parent ribbon, suggesting a substantial volume shrinkage of the reacted region. As a result of volume shrinkage, cracks can also be observed within the reacted regions, for example see the enlarged image in Fig. 10e. Furthermore, in the enlarged SEM image (Fig. 10f), nanoporous structures with characteristic sizes of $20-50 \mathrm{~nm}$ can be observed, which are interpreted as typical selective corrosion morphology [47-49]. Volume shrinkage as a result of selective corrosion, i.e., de-alloying, has been commonly detected in nanoporous structures when compared with their bulk precursors [50-53], and is consistent with the observed results in Fig. 10d and Fig. S5. As shown in the EDS images (Fig. 10g, Figs S5-S7), chemical inhomogeneities can be observed on the micrometer scale that occurred after degradation, while the as-prepared FeMGI is chemically homogeneous on this scale (Fig. S7). The cracks are oxygen poor and iron rich, demonstrating that the cracks uncover the unreacted parent ribbon matrix and expose fresh reactive sites. The reacted regions, i.e., the oxidized regions, are poor in iron and rich in copper, silicon, and oxygen, indicating that selective 

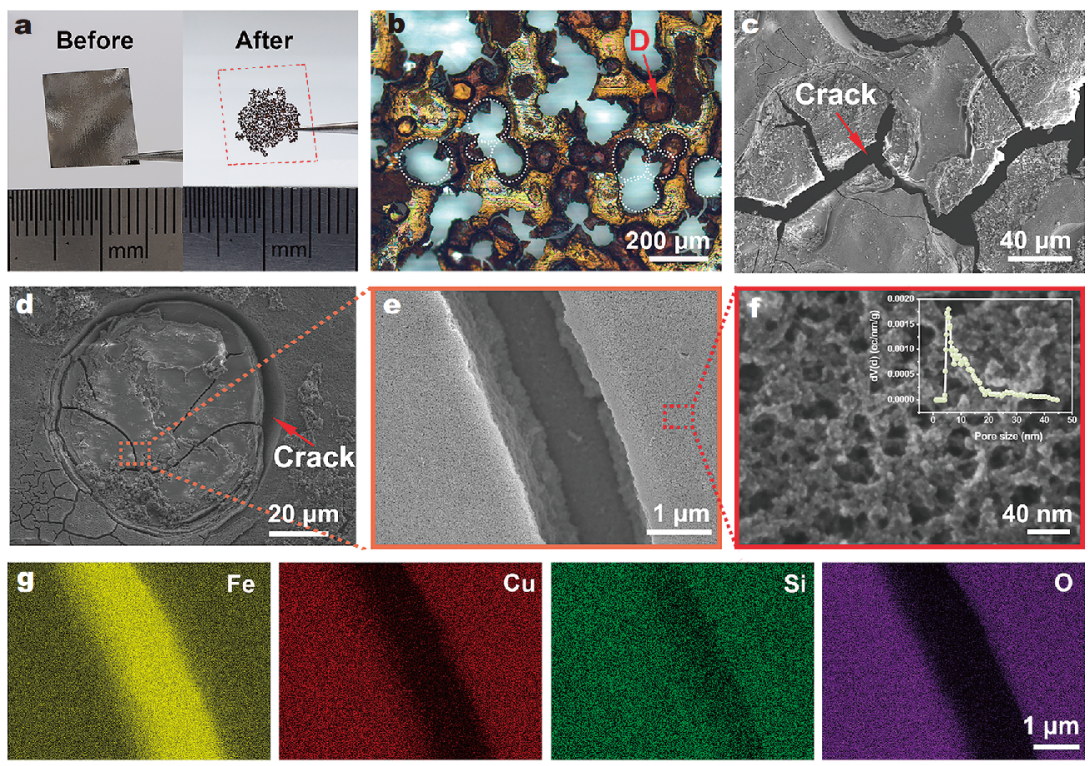

Figure 10 (a) The optical photographs of Fe-MGI before and after cycle experiment, (b) optical microscope image, (c) and (d) SEM images of FeMGI after cycle experiment, (e) and (f) further enlarged SEM images of the main reacted region. Inset of (f) is pore size distribution of the nanoporous structures. (g) Corresponding EDS images of (e).

corrosion of Fe-MGI by Orange II resembles a dissolution of $\mathrm{Fe}^{0}$, i.e., $\mathrm{Fe}^{0}$ is responsible for the decomposition of Orange II in solution.

Unlike conventional selective corrosion processes for producing a bulk 3D nanoporous structure in which the ribbons are oxidized layer by layer, in the present case, the selective corrosion of Fe-MGI is accompanied by a self-peeling off process. The morphology evolution of FeMGI after different cycles is demonstrated in Fig. 11. Prior to the reaction, the as-prepared Fe-MGI (cycle 0) has a uniform thickness of $\sim 23 \mu \mathrm{m}$ and a smooth surface. Initially, a few reactive regions, for example, regions of residual stress concentration and vulnerable regions of the oxide layer [26], react with Orange II resulting in the formation of nanoporous structures due to the selective corrosion of $\mathrm{Fe}^{0}$. The resulting nanoporous regions along with volume shrinkage experience tensile stresses from the unreacted underlying and surrounding ribbon, as indicated by the appearance of the cracks (Fig. 11a, Figs S5-S7). When the locally concentrated tensile stresses become unbearable, the cracks propagate, eventually leading to self-peeling of the nanoporous reacting regions and the precipited corrosion products (Fig. S8). This process results in the self-refreshing of the sample surface, as unreacted parent ribbon is exposed, thus increasing the number of reactive sites. Eventually, this complex series of processes leads to the development of pits on the surface. With an increase in the times of cy- cles, the number and size of such pits increase, and as a consequence, holes are observed in the ribbons after 25 cycles due to concave pits perforation (Fig. 11c). With continued cycling, the number and size of the holes increase resulting in the observed net-like ribbon structure and sustainable low coordination sites, as well as the excellent long-term reactivity of Fe-MGI.

Meanwhile, the selective consumption of $\mathrm{Fe}^{0}$ results in the formation of nanoporous reacted regions that are rich with copper compared with the unreacted parent ribbon (Fig. 10g, Figs S5-S7). It is easy to form micro-galvanic cells between the two different regions besides the nanogalvanic cells that originate from the nanoscale inhomogeneities of fresh Fe-MGI, which incorporate the unreacted parent ribbon into the degradation of Orange II. As a result, the number and size of the reacted regions increase with the number of cycles (Fig. 11). Nanoporous structures and cracks are also observed on the surface of the parent ribbon (Fig. S9), which contribute to an increase in the number of reactive sites and a further improvement in the long-term reactivity and also the degradation capability. Thus, Fe-MGI shows an increased degradation rate in some of the cycles compared with the $1^{\text {st }}$ cycle (Table S2 and Fig. S10). It is our conclusion that the superior long-term reactivity of Fe-MGI can be attributed to the self-refreshing of the material and subsequent sustainability of the reactive sites that arise from the electrochemical differences in the inhomogeneities 
a
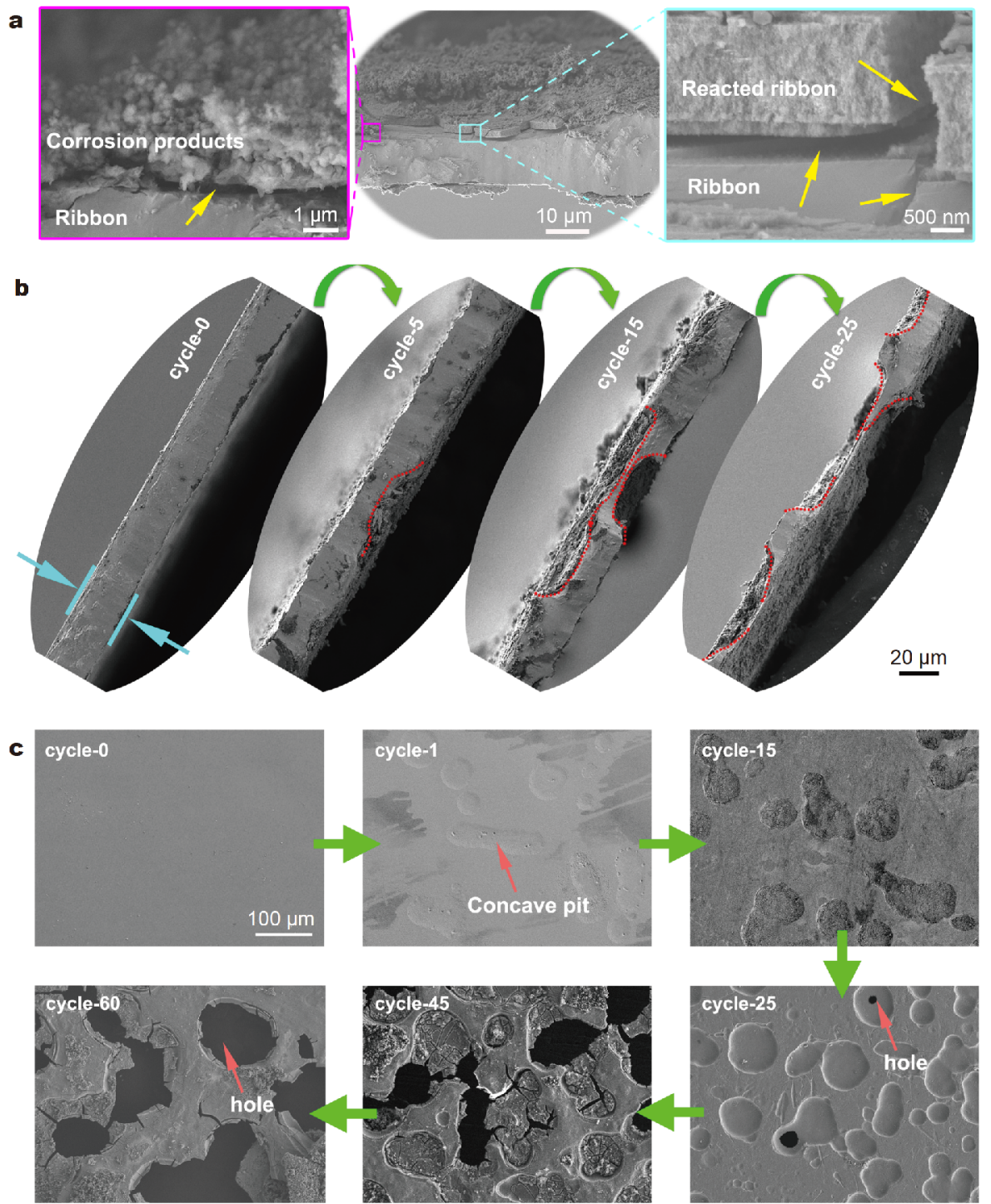

Figure 11 (a) SEM images of the cross-section of Fe-MGI after the fifteenth cycle experiment, the cracks are highlighted by yellow arrows, (b) SEM images of the cross-section of Fe-MGI before and after different cycles, (c) SEM images of the surfaces of Fe-MGI before and after different cycles.

and then the selective corrosion followed by volume shrinkage and crack formation.

The above results demonstrate that the degradation capability of Fe-MGI as a result of its long-term reactivity, high performance, and self-refreshing properties makes ZVI a candidate material for wastewater treatment. Combining the established route to MG fabrication and the requirements for field applications, a design route for the synthesis of high-performance Fe-MGI with self-refreshing capability for use in wastewater treatment is proposed below.
First, according to the extensive data collected from literature published over fifty years, three crucial rules have been established for synthesizing MGs with a uniform microstructure: (1) the alloy should contain at least three components; (2) a significant atomic size difference should exist among the constituent elements in the alloy; (3) there should be a negative enthalpy of mixing among the (major) constituent elements in the alloy system [54]. For Fe-based MGs, different alloy systems have been developed including Fe-metalloid (P, C, B, Si) MGs and $\mathrm{Fe}$-transition metal $(\mathrm{TM}=\mathrm{Co}, \mathrm{Ni}, \mathrm{Zr}, \mathrm{Mn}, \mathrm{Mo}, \mathrm{Cr}$, etc. $)$ 
MGs. Secondly, considering field applications, the fabrication of Fe-based MGs in air without the need for a protective atmosphere is essential in order to reduce the costs as much as possible. Consequently, Fe-TM systems are ruled out due to the high costs of TMs and furthermore, the elements $\mathrm{P}$ and $\mathrm{C}$ should be diminished from the composition as they are easily oxidized in air at elevated temperatures during the fabrication process. Considering these restrictions, the $\mathrm{Fe}-\mathrm{Si}-\mathrm{B}$ alloy system seems feasible, which could provide a starting material for tuning the composition and properties toward improved wastewater treatment. Thirdly, in order to enhance the long-term reactivity as well as the degradation capability, nanoscale chemical inhomogeneities as demonstrated above are crucial to facilitate wastewater treatment by introducing a local galvanic cell effect, bringing about dealloying and self-refreshing of the material. Toward this aim, $\mathrm{Cu}$ was selected in this work as a minor alloying element due to the positive enthalpy of mixing $\left(+13 \mathrm{~kJ} \mathrm{~mol}^{-1}\right)$ between $\mathrm{Fe}$ and $\mathrm{Cu}$, i.e., $\mathrm{Cu}$ can precipitate locally in an amorphous matrix of an Fe-Si-B MG [5559]. Comprehensively considering the proposed criteria, $\mathrm{Fe}_{81} \mathrm{Si}_{4} \mathrm{~B}_{14} \mathrm{Cu}_{1}$ was selected and successfully fabricated with high-performance and self-refreshing ability that promote a long cycling stability of up to 45 cycles, which may provide a new perspective to develop ZVI materials for wastewater treatment starting from the design of the MG.

\section{CONCLUSIONS}

Stimulated by the high reactivity of Fe nanoparticles and noble metal/Fe nanocomposites, here, a highly effective Fe-MG with nanoscale inhomogeneities, i.e., Fe-MGI, with the nominal composition of $\mathrm{Fe}_{81} \mathrm{Si}_{4} \mathrm{~B}_{14} \mathrm{Cu}_{1}$, was proposed and successfully prepared using a scalable meltspinning technique. It was confirmed that the newly developed Fe-MGI has a uniform amorphous structure at the submicron or above scale but with uniformly formed nanoscale inhomogeneities of $\mathrm{Cu}$-rich cluster regions. The Fe-MGI ribbons exhibit excellent long-term reactivity, high degradation capability, good adaptability, and good catalytic properties as measured in the degradation of azo dyes. These excellent properties can be attributed to the electrochemical potential differences induced by the nanoscale inhomogeneities, which contribute to the galvanic cells and selective corrosion of $\mathrm{Fe}$ MGI during the degradation process. Finally, nanoporous reacted regions are formed in the material alongside local volume shrinkage, leading to cracking and then selfpeeling of the reacted regions and the precipitation of corrosion products, i.e., self-refreshing. All of these properties toward efficient dye degradation make Fe-MGI a rather promising material compared with $\mathrm{Fe}-\mathrm{MGs}$ for field applications. In addition, and maybe even more importantly, the present study highlights a new perspective on the design and fabrication of optimized MGs with controlled performance for remediation of environmental issues through nanoscale structural modification of a uniformly global amorphous structure via suitable minor alloying.

\section{Received 19 August 2019; accepted 10 October 2019; published online 7 November 2019}

1 Safdar M, Khan SU, Jänis J. Progress toward catalytic micro- and nanomotors for biomedical and environmental applications. Adv Mater, 2018, 30: 1703660

2 Li WW, Yu HQ, He Z. Towards sustainable wastewater treatment by using microbial fuel cells-centered technologies. Energy Environ Sci, 2013, 7: 911-924

3 Zhang F, Zhang WB, Shi Z, et al. Nanowire-haired inorganic membranes with superhydrophilicity and underwater ultralow adhesive superoleophobicity for high-efficiency oil/water separation. Adv Mater, 2013, 25: 4192-4198

4 Zhu Z, Wang W, Qi D, et al. Calcinable polymer membrane with revivability for efficient oily-water remediation. Adv Mater, 2018, 30: 1801870

5 Chen B, Bi H, Ma Q, et al. Preparation of graphene- $\mathrm{MoS}_{2}$ hybrid aerogels as multifunctional sorbents for water remediation. Sci China Mater, 2017, 60: 1102-1108

6 Ding L, Zhang Z, Li Y. Synthesis and catalytic property of uraniapalladium-graphene nanohybrids. Sci China Mater, 2017, 60: 399406

7 Li K, Jiao T, Xing R, et al. Fabrication of tunable hierarchical mxene@aunps nanocomposites constructed by self-reduction reactions with enhanced catalytic performances. Sci China Mater, 2018, 61: 728-736

8 Ling L, Huang XY, Zhang WX. Enrichment of precious metals from wastewater with core-shell nanoparticles of iron. Adv Mater, 2018, 30: 1705703

9 Wang Q, Tian S, Long J, et al. Use of $\mathrm{Fe}(\mathrm{II}) \mathrm{Fe}(\mathrm{III})$-LDHs prepared by co-precipitation method in a heterogeneous-Fenton process for degradation of methylene blue. Catal Today, 2014, 224: 41-48

10 Singh P, Raizada P, Kumari S, et al. Solar-Fenton removal of malachite green with novel $\mathrm{Fe}^{0}$-activated carbon nanocomposite. Appl Catal A-General, 2014, 476: 9-18

11 Chen J, Liu W, Li Z, et al. Thermally-assisted photodegradation of lignin by $\mathrm{TiO}_{2} / \mathrm{H}_{2} \mathrm{O}_{2}$ under visible/near-infrared light irradiation. Sci China Mater, 2017, 61: 382-390

12 Miklos DB, Remy C, Jekel M, et al. Evaluation of advanced oxidation processes for water and wastewater treatment-A critical review. Water Res, 2018, 139: 118-131

13 Iskandar F, Nandiyanto A, Yun K, et al. Enhanced photocatalytic performance of brookite $\mathrm{TiO}_{2}$ macroporous particles prepared by spray drying with colloidal templating. Adv Mater, 2007, 19: 14081412

14 Kumar A, Sharma G, Naushad M, et al. Spion/ $\beta$-cyclodextrin coreshell nanostructures for oil spill remediation and organic pollutant 
removal from waste water. Chem Eng J, 2015, 280: 175-187

15 Zhang X, Wei W, Zhang S, et al. Advanced 3D nanohybrid foam based on graphene oxide: Facile fabrication strategy, interfacial synergetic mechanism, and excellent photocatalytic performance. Sci China Mater, 2019, 62: 1888-1897

16 Gillham RW, O'Hannesin SF. Enhanced degradation of halogenated aliphatics by zero-valent iron. Ground Water, 1994, 32: 958967

17 Guan X, Sun Y, Qin H, et al. The limitations of applying zerovalent iron technology in contaminants sequestration and the corresponding countermeasures: The development in zero-valent iron technology in the last two decades (1994-2014). Water Res, 2015, 75: 224-248

18 Wang JQ, Liu YH, Chen MW, et al. Rapid degradation of azo dye by Fe-based metallic glass powder. Adv Funct Mater, 2012, 22: 2567-2570

19 Qin XD, Zhu ZW, Liu G, et al. Ultrafast degradation of azo dyes catalyzed by cobalt-based metallic glass. Sci Rep, 2015, 5: 18226

20 Jia Z, Duan X, Qin P, et al. Disordered atomic packing structure of metallic glass: Toward ultrafast hydroxyl radicals production rate and strong electron transfer ability in catalytic performance. Adv Funct Mater, 2017, 27: 1702258

21 Wang Q, Chen M, Lin P, et al. Investigation of FePC amorphous alloys with self-renewing behaviour for highly efficient decolorization of methylene blue. J Mater Chem A, 2018, 6: 10686-10699

22 Tang Y, Shao Y, Chen N, et al. Rapid decomposition of Direct Blue 6 in neutral solution by Fe-B amorphous alloys. RSC Adv, 2015, 5: 6215-6221

23 Tang $\mathrm{Y}$, Shao $\mathrm{Y}$, Chen $\mathrm{N}$, et al. Insight into the high reactivity of commercial $\mathrm{Fe}-\mathrm{Si}-\mathrm{B}$ amorphous zero-valent iron in degrading azo dye solutions. RSC Adv, 2015, 5: 34032-34039

24 Wang PP, Wang JQ, Huo JT, et al. Fast degradation of azo dye by nanocrystallized Fe-based alloys. Sci China-Phys Mech Astron, 2017, 60: 076112

25 Debenedetti PG, Stillinger FH. Supercooled liquids and the glass transition. Nature, 2001, 410: 259-267

26 Chen SQ, Shao Y, Cheng MT, et al. Effect of residual stress on azo dye degradation capability of Fe-based metallic glass. J NonCrystalline Solids, 2017, 473: 74-78

27 Chen S, Chen N, Cheng M, et al. Multi-phase nanocrystallization induced fast degradation of methyl orange by annealing Fe-based amorphous ribbons. Intermetallics, 2017, 90: 30-35

28 Chen S, Yang G, Luo S, et al. Unexpected high performance of Febased nanocrystallized ribbons for azo dye decomposition. J Mater Chem A, 2017, 5: 14230-14240

29 Liang SX, Jia Z, Liu YJ, et al. Compelling rejuvenated catalytic performance in metallic glasses. Adv Mater, 2018, 30: 1802764

$30 \mathrm{Ke} \mathrm{Y,He} \mathrm{C,} \mathrm{Zheng} \mathrm{H,} \mathrm{et} \mathrm{al.} \mathrm{The} \mathrm{time-of-flight} \mathrm{small-angle} \mathrm{neutron}$ spectrometer at China spallation neutron source. Neutron News, 2018, 29: 14-17

31 Matsuura M, Nishijima M, Takenaka K, et al. Evolution of fcc Cu clusters and their structure changes in the soft magnetic $\mathrm{Fe}_{85.2} \mathrm{Si}_{1}$ $\mathrm{B}_{9} \mathrm{P}_{4} \mathrm{Cu}_{0.8}$ (NANOMET) and FINEMET alloys observed by X-ray absorption fine structure. J Appl Phys, 2015, 117: 17A324

32 Sharma $\mathrm{P}$, Zhang $\mathrm{X}$, Zhang $\mathrm{Y}$, et al. Competition driven nanocrystallization in high $B_{\mathrm{s}}$ and low coreloss $\mathrm{Fe}-\mathrm{Si}-\mathrm{B}-\mathrm{P}-\mathrm{Cu}$ soft magnetic alloys. Scripta Mater, 2015, 95: 3-6

33 Abaidia SEH, Wiedenmann A. Thermal stability of the bulk metallic glass $\mathrm{Zr}_{46.75} \mathrm{Ti}_{8.25} \mathrm{Cu}_{7.5} \mathrm{Ni}_{10} \mathrm{Be}_{27.5}$ studied by SANS. Physica BCondensed Matter, 2000, 276-278: 454-455
34 Jia Z, Zhang WC, Wang WM, et al. Amorphous $\mathrm{Fe}_{78} \mathrm{Si}_{9} \mathrm{~B}_{13}$ alloy: An efficient and reusable photo-enhanced Fenton-like catalyst in degradation of cibacron brilliant red 3B-A dye under UV-vis light. Appl Catal B-Environ, 2016, 192: 46-56

35 Xie S, Huang P, Kruzic JJ, et al. A highly efficient degradation mechanism of methyl orange using Fe-based metallic glass powders. Sci Rep, 2016, 6: 21947

36 Wang JQ, Liu YH, Chen MW, et al. Excellent capability in degrading azo dyes by MgZn-based metallic glass powders. Sci Rep, 2012, 2: 418

37 Wang P, Wang JQ, Li H, et al. Fast decolorization of azo dyes in both alkaline and acidic solutions by Al-based metallic glasses. J Alloys Compd, 2017, 701: 759-767

38 Li C, Zhuang Z, Huang F, et al. Recycling rare earth elements from industrial wastewater with flowerlike nano- $\mathrm{Mg}(\mathrm{OH})_{2}$. ACS Appl Mater Interfaces, 2013, 5: 9719-9725

39 Liu M, Wang Y, Chen $\mathrm{L}$, et al. $\mathrm{Mg}(\mathrm{OH})_{2}$ supported nanoscale zero valent iron enhancing the removal of $\mathrm{Pb}$ (II) from aqueous solution. ACS Appl Mater Interfaces, 2015, 7: 7961-7969

40 Jia Z, Wang Q, Sun L, et al. Attractive in situ self-reconstructed hierarchical gradient structure of metallic glass for high efficiency and remarkable stability in catalytic performance. Adv Funct Mater, 2019, 29: 1807857

41 Mielczarski JA, Atenas GM, Mielczarski E. Role of iron surface oxidation layers in decomposition of azo-dye water pollutants in weak acidic solutions. Appl Catal B-Environ, 2005, 56: 289-303

42 Cai C, Zhang H, Zhong X, et al. Ultrasound enhanced heterogeneous activation of peroxymonosulfate by a bimetallic $\mathrm{Fe}-\mathrm{Co} /$ SBA-15 catalyst for the degradation of Orange II in water. J Hazard Mater, 2015, 283: 70-79

43 Liang SX, Jia Z, Zhang WC, et al. Rapid malachite green degradation using $\mathrm{Fe}_{73.5} \mathrm{Si}_{13.5} \mathrm{~B}_{9} \mathrm{Cu}_{1} \mathrm{Nb}_{3}$ metallic glass for activation of persulfate under UV-vis light. Mater Des, 2017, 119: 244-253

44 Deng Z, Zhang XH, Chan KC, et al. Fe-based metallic glass catalyst with nanoporous surface for azo dye degradation. Chemosphere, 2017, 174: 76-81

45 Jia Z, Duan X, Zhang W, et al. Ultra-sustainable $\mathrm{Fe}_{78} \mathrm{Si}_{9} \mathrm{~B}_{13}$ metallic glass as a catalyst for activation of persulfate on methylene blue degradation under UV-vis light. Sci Rep, 2016, 6: 38520

46 Fujita T, Guan P, McKenna K, et al. Atomic origins of the high catalytic activity of nanoporous gold. Nat Mater, 2012, 11: 775-780

47 Detsi E, Cook JB, Lesel BK, et al. Mesoporous $\mathrm{Ni}_{60} \mathrm{Fe}_{30} \mathrm{Mn}_{10}$-alloy based metal/metal oxide composite thick films as highly active and robust oxygen evolution catalysts. Energy Environ Sci, 2016, 9: 540-549

48 Tan Y, Wang H, Liu P, et al. 3D nanoporous metal phosphides toward high-efficiency electrochemical hydrogen production. Adv Mater, 2016, 28: 2951-2955

49 Paschalidou EM, Celegato F, Scaglione F, et al. The mechanism of generating nanoporous $\mathrm{Au}$ by de-alloying amorphous alloys. Acta Mater, 2016, 119: 177-183

50 Gupta G, Thorp JC, Mara NA, et al. Morphology and porosity of nanoporous $\mathrm{Au}$ thin films formed by dealloying of $\mathrm{Au}_{x} \mathrm{Si}_{1-x}$. J Appl Phys, 2012, 112: 094320

51 Lu X, Bischoff E, Spolenak R, et al. Investigation of dealloying in $\mathrm{Au}-\mathrm{Ag}$ thin films by quantitative electron probe microanalysis. Scripta Mater, 2007, 56: 557-560

52 Parida S, Kramer D, Volkert CA, et al. Volume change during the formation of nanoporous gold by dealloying. Phys Rev Lett, 2006, 97: 035504 
53 Suryanarayana C, Inoue A. Iron-based bulk metallic glasses. Int Mater Rev, 2013, 58: 131-166

54 Jafari S, Beitollahi A, Yekta BE, et al. Atom probe analysis and magnetic properties of nanocrystalline $\mathrm{Fe}_{84.3} \mathrm{Si}_{4} \mathrm{~B}_{8} \mathrm{P}_{3} \mathrm{Cu}_{0.7}$. J Alloys Compd, 2016, 674: 136-144

55 Hono K, Inoue A, Sakurai T. Atom probe analysis of $\mathrm{Fe}_{73.5} \mathrm{Si}_{13.5}$ $\mathrm{B}_{9} \mathrm{Nb}_{3} \mathrm{Cu}_{1}$ nanocrystalline soft magnetic material. Appl Phys Lett, 1991, 58: 2180-2182

56 Hono K, Ping DH, Ohnuma M, et al. Cu clustering and Si partitioning in the early crystallization stage of an $\mathrm{Fe}_{73.5} \mathrm{Si}_{13.5} \mathrm{~B}_{9} \mathrm{Nb}_{3} \mathrm{Cu}_{1}$ amorphous alloy. Acta Mater, 1999, 47: 997-1006

57 Ayers JD, Harris VG, Sprague JA, et al. The local atomic order of $\mathrm{Cu}$ and $\mathrm{Fe}$ in heat treated $\mathrm{Fe}_{73.5} \mathrm{Nb}_{3} \mathrm{Cu}_{1} \mathrm{Si}_{13.5} \mathrm{~B}_{9}$ ribbons. IEEE Trans Magn, 1993, 29: 2664-2666

58 Ayers JD, Harris VG, Sprague JA, et al. On the role of $\mathrm{Cu}$ and $\mathrm{Nb}$ in the formation of nanocrystals in amorphous $\mathrm{Fe}_{73.5} \mathrm{Nb}_{3} \mathrm{Cu}_{1} \mathrm{Si}_{13.5}$ $\mathrm{B}_{9}$. Appl Phys Lett, 1994, 64: 974-976

Acknowledgements This work was financially supported by the National Natural Science Foundation of China (NSFC, 51871129 and 51571127), the National Key Basic Research and Development Programme (2016YFB0300502), and the Natural Science Foundation of Jiangsu Province (BK20190480). The author Chen SQ appreciates the help from Heng-Wei Luan, Jia-Cheng Ge, Si-Nan Liu and Dr. Sudheer Kumar Yadav.

Author contributions Chen SQ designed and performed most of the experiments and wrote the manuscript with support from Hahn $\mathrm{H}$, Shao Y, Yao KF and Zhao W. Hui KZ and Dong LZ performed the experiments of degradation of azo dyes. Li Z prepared the ribbons. Zhang QH and $\mathrm{Gu} \mathrm{L}$ performed the TEM experiments. Lan $\mathrm{S}$ and Ke $\mathrm{Y}$ conducted the SANS experiments. Shao Y, Hahn H and Yao KF conceived and supervised the study. All authors contributed to the general discussion.

Conflict of interest The authors declare that they have no conflict of interest.

Supplementary information Supporting information is available in the online version of the paper.

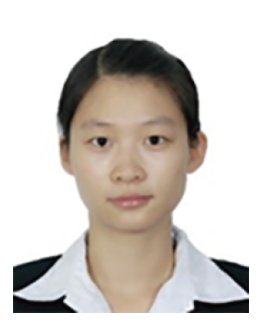

Shuang-Qin Chen received her PhD degree in materials science from Tsinghua University under the supervision of Prof. Kefu Yao in 2018. Currently, she is working at Nanjing University of Science and Technology as an assistant professor. Her present research interests focus on the catalytic properties of metallic glasses.

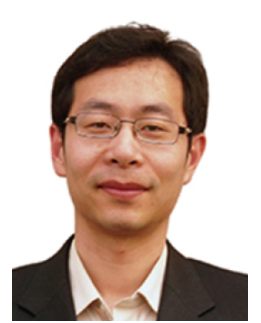

Yang Shao is an associate professor of the School of Materials Science and Engineering at Tsinghua University. He received his BE degree in 2002 and Master degree in 2004 from Tsinghua University, and received his $\mathrm{PhD}$ degree in 2009 from McMaster University. After postdoc research in the Canadian Centre for Electron Microscopy, he joined in Tsinghua University in 2010. Dr. Shao's research interests mainly focus on the fundamentals and applications of advanced metallic alloys.

\section{纳米尺度非均匀性诱导自更新铁基非晶合金具有 优异的长期反应活性}

陈双琴 ${ }^{1,2}$, 惠可榛 ${ }^{1 \dagger}$, 董梁正 ${ }^{1 \dagger}$, 李准 ${ }^{3}$, 张庆华 $^{4}$, 谷林 ${ }^{4}$, 赵威 ${ }^{1}$, 兰司 ${ }^{2}$, 柯于斌, 郡洋 ${ }^{1^{*}}$, Horst Hahn ${ }^{2,5}$, 姚可夫 ${ }^{1^{*}}$

摘要 铁基非晶合金作为亚稳态新型零价铁, 具有高活性亚稳态结 构、较大的残余应力和高密度低配位点等特性, 在催化和废水处 理中引起了广泛的关注; 但由于腐蚀产物沉淀覆盖活性位点, 非晶 合金的反应活性随着时间的推移而逐渐降低，导致耐用性差. 腐蚀 产物沉淀造成长期反应活性降低也是阻碍传统晶态零价铁技术在 废水处理领域应用的主要问题之一. 本文通过在铁基非晶合金中 引入纳米尺度的化学不均匀性, 有助于构成局部原电池效应, 加速 电子在降解过程中的转移, 可以有效地克服这一问题. 更重要的是, 非晶合金中的零价铁被选择性腐蚀/脱合金, 导致反应区域局部体 积收缩和裂纹形成, 裂纹扩展使沉淀腐蚀产物和反应区域自剥落. 因此, 可以连续提供新的低配位, 消除质量传递和反应活性恶化的 问题. 本文所制备的具有成分不均匀的铁基非晶合金即使在中性 溶液中也具有良好的长期反应活性和自更新性能. 研究结果不仅 为废水处理提供了一种新材料, 而且为设计高活性零价铁材料提 供了一种新思路. 